\title{
Global climate change, air pollution, and women's health
}

\author{
K. Duncan \\ University of Toronto, Canada
}

\begin{abstract}
Climate change will disturb the Earth's physical systems (e.g. weather patterns) and ecosystems (e.g. disease vector habitats); these disturbances, in turn, will pose direct and indirect risks to human health. Direct risks involve climatic factors that impinge directly on human biology. Indirect risks do not entail direct causal connections between climatic factors and human biology.

The Third Assessment Report (TAR) of the Intergovernmental Panel on Climate Change elucidates the potential human health impacts of global climate change at both a population and regional level.

The impacts on child health, adult health, and the health of the elderly, however, remain largely unexplored. A paucity of research regarding women's health is also extant, despite increasing interest in the issue.

According to the TAR, climate change is projected to affect such key issues as air quality, food yields and nutrition, water-related infectious diseases, and water supply. Exposure to cooking fuels, access to food, distribution of food within the family, and choice of water sources is often determined by gender. Thus, women's contributions may, in some cases, make them more vulnerable than their male counterparts to climate change. Moreover, it is anticipated that health care will significantly help people adapt to climate change. Unfortunately, not everyone has adequate health care. In some countries, fewer than $25 \%$ of women visit health-care professionals.

Climate change is likely to have a strong, positive (worsening) effect on smog and acidic deposition; climate change is likely to have some effect on suspended particulates.

In light of the foregoing, this paper addresses the interrelated and neglected areas of global climate change, air pollution, and women's health.

Keywords: global climate change, air pollution, thermal extremes, women's health.
\end{abstract}




\section{Women's health}

It is imperative to address the future of women's health; human health depends considerably on investing in the well-being of women, as their physical condition largely determines the health of their children who are the adults of tomorrow (Duncan [1]; and World Health Organization [2-4]). Moreover, being female or male has a major impact on an individual's health and well-being. For example, the natural course of a disease may be different in women and men, women and men may respond differently to illness, society may respond differently to sick women and men, women and men may have different access to healthcare, may be treated differently by health providers, and may respond differently to treatment (Duncan [5]).

\section{Environment and women's health}

Since the early 1980's, considerable attention has been devoted to the relationship between the environment and women's health because the survival of women and their families remains closely linked to the health of fisheries, forests, land, and other natural resources. Therefore, exposure to poor environments often leads to the development of disease and ill health. For example, air pollution in Ukraine has been linked to $21 \%$ of all illnesses affecting women and children, and water pollution in Uzbekistan has led to an increase in complications in pregnancy and an increase in birth defects.

The Platform for Action, adopted in Beijing in 1995, called for a greater recognition of women as guardians of the environment, a decrease of environmental risks to women, and enhanced participation of women in the management of environmental resources (Division for the Advancement of Women [6]).

Despite increasing interest in the issue of the environment and women's health, there remains a lack of training in this area, and a dearth of information regarding women and climate change (one of today's most pressing global environmental issues) (Stipp [7]; Houghton et al., [8]; and Climate Change Solutions [9]).

\subsection{Climate change and women}

For the first twenty years that climate change was debated, gender issues were not even on the agenda-although women (1) are more dependent than men on primary resources (e.g. agriculture and fisheries) that are threatened by changes in climate, and (2) are generally poorer financially than men (Duncan [10]).

Women are, however, particularly vulnerable to climate change. For example, women often shoulder the responsibility for the household water supply and its purification. In Kenya, carrying water may use up to $85 \%$ of a female's daily energy intake (Women's Environment and Development Organization [11]; and World Health Organization [3]). 
'She does not know her age, but is probably about twelve years old. She visits the same water hole at 05:30 each day in order to collect water for her family - despite its being muddy and being used by animals. She does not boil the water, as a nearby man tells her that it 'contains no living things,

(World Health Organization [12]).

Women collect water and manage its use in households. They also farm irrigated and rain-fed crops, and they know water's availability, quality, and reliability (Jahnavi [13]).

As a result of the division of labour, women often come in contact with polluted or poor-quality water, and are therefore more vulnerable to waterrelated diseases than men. These diseases kill between five and twelve million people per year, most of them women and children. And millions more are sickened with diarrhoea, hepatitis, malaria, schistosomiasis, and trachoma that are preventable through access to clean water and health care information (Kumar and Clark [14]; Meade et al., [15]; Women's Environment and Development Organization [11]; and World Health Organization [3]).

In the past ten years diarrhoea killed more children than all those lost to armed conflict since the Second World War. In fact a child dies every 15 seconds from diarrhoea - mainly due to poor sanitation and poor water supply (Duncan [5]).

It is women who bear the main burden of caring for those who are ill. But when it comes to decision-making about climate change, women in most parts of the world remain almost invisible (Duncan [5, 10]; and Roehr [16]).

COP-8, however, at last recognized that women are extremely vulnerable to climate change and that they may bear an unreasonably large share of the adaptation burden. And on March $6^{\text {th }}$ 2003, a Canada-China Workshop on Gender Equality and Climate Change was held in China--a possible first step to ensuring that women become active partners in vulnerability studies, mitigation efforts, and climate change adaptation (Duncan [10]).

\section{Climate change}

Global average surface temperature increased by $0.6+/-0.2^{\circ} \mathrm{C}$ over the last century. Rainfall increased in mid- to high-latitudes, and episodes of El Nino increased in frequency, intensity, and persistence since the mid-1970s (Houghton et al., $[8,17])$.

Global mean temperature is projected to increase $1.4-5.8^{\circ} \mathrm{C}$ over the coming century, a rise greater than any increase experienced by humans during the past 10,000 years, and global sea level is projected to rise $9-88 \mathrm{~cm}$ by the year 2100 (Houghton et al., [8]). [It should be noted that preparations for the Fourth Assessment Report by the Intergovernmental Panel on Climate Change are still underway, and that the final reports are due in 2007 (Intergovernmental Panel on Climate Change [18]).]

Susceptibility to climate change differs across countries, populations, regions and sectors (Cohen and Miller [19]). For example, an increase in sea level will 
significantly increase the number of people vulnerable to floods. Currently, some 46 million people per year experience flooding due to storm surges; a 50centimetre sea-level rise would increase the number of vulnerable individuals to 92 million, and a one-metre rise would increase the number to 118 million (McCarthy et al., [20]).

\section{Climate change and human health}

Climate change will disturb the Earth's physical systems (e.g. weather patterns) and ecosystems (e.g. disease-vector habitats). The disturbances will, in turn, pose direct and indirect risks to human health. Direct risks involve climatic factors, such as extreme thermal events and severe weather that impinge directly on human biology. Indirect risks, including air pollution, decreases in food production, reductions in water quality and quantity, and vector-borne disease, do not entail causal connections between climatic factors and human biology (McMichael and Haines [21]; and Duncan et al., [22]).

Climate change is a growing concern to the World Health Organization because of its potentially serious health consequences, its disproportionate impact on poor countries, and its disproportionate impact on poor and vulnerable groups. For example, a total of 1.3 billion people in the developing world live below the poverty threshold - seventy \% of these are women (World Health Organization $[2,23])$.

\section{Air pollution and human health}

Our protective and life-giving atmosphere is no longer in its natural form; that is, humans have altered its chemistry. As early as 1273, King Edward 1 issued a proclamation forbidding the use of impure sea coal, which produced considerable soot and sulphur dioxide when burned. One person was reputedly executed for violating his decree (Mannion [24]).

In spite of the King's mandate, English coal use increased during the fifteenth and sixteenth centuries, and in 1661, the prominent scientist John Evelyn wrote an essay condemning London's filthy air. As industrialization progressed, the smoke problem worsened, and by the 1850's, London was notorious for its dangerous 'pea-soup' fogs. In 1873, one such fog claimed the lives of 700 people, and in 1911, 1150 Londoners succumbed to another deadly haze. More recently, in 1952, a sulphurous London fog killed 4000 people (Hidore [25]; and Ahrens [26]).

Air pollutants are airborne substances, either solids, liquids or gases, that occur in concentrations high enough to threaten the health of people and animals, harm vegetation and structures, or toxify a given environment. Airborne pollutants come from both natural sources and human activities. Examples of natural sources include particulate matter from dust storms, salt from ocean waves, soot from forest fires, and volcanic ash. Human-induced pollution enters the atmosphere from both fixed sources, such as homes, industrial complexes, offices, and power plants, and mobile sources, such as jet aircraft, motor vehicles, and ships (Duncan et al., [22]). 
The United States Environmental Protection Agency reported in 1989 on the magnitude of industrial injection of chemicals into the atmosphere. In the United States, a total of 2.7 billion pounds of pollutants, of which 360 million pounds were suspected of being carcinogenic, were released into the atmosphere in 1987 alone. A total of 1600 industrial facilities in 46 states emitted carcinogens into the air, and 125 of these plants released more than 400,000 pounds of chemicals per year (Hidore [25]). In 1997, approximately 107 million people in the United States lived in counties that did not meet air quality standards for at least one regulated pollutant.

Acid precipitation refers to precipitation acidified by atmospheric pollutants, such as sulphur dioxide $\left(\mathrm{SO}_{2}\right)$ and nitrogen oxides $\left(\mathrm{NO}_{\mathrm{x}}\right)$, emitted from smelters and fossil-fuel power stations. These pollutants are converted chemically to sulphuric and nitric acid in the atmosphere. The contaminants may travel long distances before being washed out of the atmosphere in drizzle, freezing rain or snow, hail, or rain (Duncan et al., [22]).

In 1992, EEO provided the following information regarding acid rain in Canada: more than $80 \%$ of Canadians live in areas with 'high acid rain-related pollution levels'. A recent study found that long-term exposure to acid aerosols had a deleterious effect on lung development, growth, and function of children living in 24 communities in Canada and the United States (Dockery et al., [27]). A total of 300,000 Canadian lakes are vulnerable to acid precipitation, 150,000 lakes are being damaged by acid rain, and 14,000 lakes are acidified (Duncan et al., [22]).

Air toxics, including aerosols (fine solid particles and liquid droplets combined), gases, or particulates, may have immediate or long-term adverse effects on human health (e.g. birth defects, cancer, nervous system problems) and the environment (e.g. contamination of food, soil, or water).

One of the most well-known accidental releases of toxics occurred on the night of 2-3, December 1984, when 40 tons of methyl isocyanate (an extremely toxic agent which, in the short term, may cause bronchial pneumonia, bronchitis, pulmonary oedema, and even death) escaped from Union Carbide Corporation's pesticide factory in Bhopal, India, and spread over the surrounding city of nearly 900,000 people. Hundreds of thousands were injured, and thousands died.

Although it is impossible to know the true number of sickened and dead, 7000 shrouds purchased by grieving families in the days following the disaster may give a better estimate of those killed than the approximation of 2000-4000 dead commonly quoted. The long-term health effects are also difficult to evaluate; however, the International Medical Commission on Bhopal estimated that in 1994, upwards of 50,000 people remained partially or totally disabled (Dhara and Dhara [28]).

Air toxics include a wide variety of chemicals, such as polychlorinated biphenyls (PCBs), trace metals, such as arsenic, lead, and mercury, and unburned hydrocarbons, such as benzene, dioxins, furans, formaldehyde, polycyclic aromatic hydrocarbons (PAHs), and trichloroethylene. Air toxics are released by sources such as chemical plants, dry cleaners, printing plants, and motor vehicles. 
Particulate matter is a term used to describe the material that can be filtered from the air. Particulate matter includes particles such as ash, dust, fibre, pollen, soot, and other tiny fragments of solid material that are dispersed into the atmosphere by natural sources and human activities. In general, these particulates are produced by human activities, including the burning of diesel fuel by trucks and buses, incineration of garbage, industrial processes (such as agricultural burning, mining operations, and steelmaking), mixing and application of fertilizers and pesticides, road construction, and thermal-power generation plants.

Particulate matter is categorized by size. Fine particulates include the particle sizes PM 2.5 and PM10. PM 2.5 refers to particles at or below a diameter of 2.5 micrometres (um), whereas PM10 refers to particles that are 10 um or less in diameter. Fine particulates are associated with impaired lung function, increased hospitalizations, pulmonary function decrements, pulmonary inflammation, reduced exercise capacity, and even increased mortality from cardiopulmonary disease and lung cancer (Duncan et al., [22]).

Currently, in most large cities in the developing world, airborne particulate levels are five times higher than in developed countries, and more than three million people die each year as a result of air pollution (United Nations Department of Economic and Social Affairs [29]). For example, in Sao Paulo and Rio de Janeiro, 27 million people are exposed to high levels of particulate air pollution, which is thought to cause 4000 deaths annually (Regional Office for Latin America and the Caribbean [30]).

Photochemical smog is produced through complex photochemical reactions when two pollutants, hydrocarbons and nitrogen oxides, react in the presence of strong sunlight, high temperatures (above $18^{\circ} \mathrm{C}$ ), and stable air masses. Groundlevel ozone is one of the major components of photochemical smog (Duncan et al., [22]; and Ahrens [26]).

More than half of all Canadians live in areas in which ground-level ozone may reach unacceptable levels during the summer months. Peak one-hour concentrations during typical pollution episodes in the Windsor-Quebec City corridor often reach $150 \mathrm{ppb}$. Windsor exceeds standards for ozone air quality (82 ppb) 30 days per year on average (Duncan et al., [22]).

Possible health effects of smog range from severe, uncommon events (e.g. death) to mild, common effects (e.g. eye, nose, and throat irritation) and asymptomatic changes of unclear clinical significance (e.g. small pulmonary function decrements and pulmonary inflammation). Ozone may pose a particular threat, however, to those who already suffer from respiratory problems, such as asthma, chronic bronchitis, or emphysema; these conditions affect about $7.5 \%$ of the Canadian population (Stieb et al., [31]; and Duncan et al., [22]).

Indoor air pollution is also a problem in much of the world. About 2.5 million women and children die each year from acute respiratory infections due to indoor air pollution. Traditional cook stoves produce carbon monoxide, hydrocarbons, pollutants, and smoke that affect the health of those who tend the stoves. More than two-thirds of deaths are associated with indoor air pollution, which affects mostly women and children (Duncan [10]). 
In South Africa, children living in homes with wood stoves are almost five times more likely than others to develop respiratory infections severe enough to require hospitalization. In rural Mexico, coal smoke exposure can increase lung cancer risks by a factor of nine or more, and in India, smoke exposure has been associated with a $50 \%$ increase in stillbirths. (Improved biomass cook stoves, such as the Upesi stove developed in Kenya, not only conserve biomass resources and reduce the time and energy needed for collecting fuel and cooking, but also emit $60 \%$ less smoke.) (United Nations Department of Economic and Social Affairs [29])

Air pollution harms more than 1.1 billion people each year, and kills three million annually. Ninety percent of these deaths occur in developing countries, where air pollution is at its worst; for example, Mexico City exceeded the ozone standard (0.1 parts per million) for 1400 hours over 145 days in 1991 (Duncan [10]).

Chen et al., [32] speculate that air pollution may affect females more than males because females may have a greater deposition of inhaled particles in their lungs, leading to increased health risks. The authors also theorize that females may be more sensitive to airborne pollution since they have fewer red blood cells than males, and thus may be more sensitive to the toxicological influences of air pollutants.

\section{Climate change and air pollution}

Climate change is likely to have a strong, positive (worsening) effect on smog and acidic deposition; climate change is likely to have some effect on suspended particulates. Health effects range from severe, uncommon events (e.g. death) to mild, common events (e.g. eye, nose and throat irritation). Worsening air quality will therefore further impair the health of women and children who already suffer from indoor air pollution.

\section{Climate change, air pollution, thermal extremes, and women}

In a warmer world, heat waves are expected to become more frequent and severe (Duncan et al., [22]). A warmer climate and thermal extremes may increase urban air pollution, and will affect local and regional air pollution concentrations (Suzuki [33]).

More specifically, warmer temperatures are expected to be accompanied by an increase in primary and secondary pollutants (McMichael and Haines [21]; and Patz and Kahliq [34]). For example, heat and sunlight are significant variables in the production of smog (Suzuki [33]); smog has the potential to aggravate pre-existing cardiovascular and respiratory conditions (Burnett et al., $[35,36]$; and Bransford and Lai [37]), and potentially increase the number of hospitalizations (Duncan et al., [22]). 
Particularly vulnerable people include the young, the elderly, the poor, the frail and the ill, and those who live in the top floors of apartment buildings and who lack access to air conditioning, especially in large urban areas. Other vulnerable people are those who take medications that affect their body's thermoregulatory ability (Cohen and Miller [19]).

Significant qualitative and quantitative data suggest that men and women differ in their response to extreme thermal environments. Women sweat less, have a higher working metabolic rate, and have thicker subcutaneous fat that prevents them from cooling themselves as efficiently as men. Women, as a population, are therefore less tolerant of an imposed heat stress; acclimatization, body size, and cardiovascular fitness are important factors in determining tolerance.

In 1984 , mean daily temperatures rose from $21.1^{\circ} \mathrm{C}$ in the preceding week to $28.9^{\circ} \mathrm{C}$ during a heat wave in New York. Throughout the extreme weather, noninstitutionalized elderly, particularly women, were at highest risk of heatassociated death; among those aged 75-84 years, death rates rose 39\% for men, and $66 \%$ for women; among those over 85 years old, increases were $13 \%$ for men and 55\% for women (MMWR [38]).

More recently, a heat wave struck France in early August 2003 after warmer than average temperatures in June and July. Total excess mortality from1 August and 20 August was 14 802; in all age groups female mortality was 15-20\% higher than male mortality (Duncan [10]).

Gender significantly affects the daily lives of women and men, before, during, and after an extreme event. In most societies, men tend to have greater access to key survival and recovery leaving women more vulnerable to natural events. Particularly vulnerable women include battered women/women at risk of violence, immigrant women/women with language barriers, indigenous women/minority women, isolated women/rural women, poor or low-income women, refugee women and the homeless, senior/frail women, women heading households/single mothers/widows, and women with disabilities (Duncan [10]).

Gender-specific health impacts of extreme weather events include: mental stress as a result of providing emotional care during and after the crisis, and increased violence (Duncan [5]).

Police reports of domestic violence in the seven months following the Mt. St. Helen's eruption (1980) increased by 46\%. Following the 1993 Missouri floods, the average state turn-away rate at shelters rose $111 \%$, programs sheltered $400 \%$ more flood-impacted women and children than anticipated, and in 1998, a Montreal Police Chief reported that one in four calls received during the 1997 ice storm were from abused women (Duncan [10]).

More recently, Simister and Cooper [39] demonstrated seasonal patterns in workplace events (e.g. 'quitting jobs' and strikes) and violent crime.

As discussed in section six, women are at increased risk during air pollution episodes. Increasing air temperatures (with possible heat-related morbidity, mental stress, and violence) may exacerbate the pollution health impacts on women. 
Fortunately, heat-related health impacts can be reduced through behavioural adaptations, such as the use of air conditioners, increased intake of fluids, the development of community-wide heat emergency plans, and improved heat warning systems (Cohen and Miller [19]). But, these measures are often unavailable to women already at risk for air pollution.

\section{Adaptation}

Regrettably, those with the least resources - that is, the poorest segments of societies--have the least capacity to adapt and are the most vulnerable. Vulnerability is likely to be differentiated by gender.

Adaptation is necessary at all scales to complement climate change mitigation efforts. The ability to adapt and cope with climate change is a function of the ability to spread risk, equity, information, infrastructure, institutions, technology, and wealth.

According to Amartya Sen, 'The voice of women is critically important for the world's future - not just for women's future'. The equal participation of women is absolutely necessary to meet changing climatic conditions.

\section{References}

[1] Duncan, K. (Forthcoming). Environment and Health: Corporate Contributions to Our Common Future.

[2] World Health Organization. 2002. The World Health Report 2002. Reducing Risks, Promoting Healthy Life. WHO: Geneva.

[3] World Health Organization. 2004. Maternal Mortality in 2000: Estimates Developed by WHO, UNICEF, UNFPA. WHO.

[4] World Health Organization. 2005. Make Every Mother and Child Count: A Toolkit for Organizers of Activities. WHO/RHR/04.10.

[5] Duncan, K. 2004. Initial links: climate change, water, women, and health. Water and Climate Change: Knowledge for Better Adaptation. Canadian Water Resources Association Conference Proceedings.

[6] Division for the Advancement of Women. Department of Economic and Social Affairs. Nd. Fourth world conference on women. Platform for action. http://www.un.org/womenwatch/daw/beijing/platform/index.html. 29/07/06.

[7] Stipp, D. 1997. At risk: profits and jobs. Fortune December 8, 1997.

[8] Houghton, J., Ding, Y., Griggs, D. et al. (eds). 2001. Climate Change 2001: The Scientific Basis. Contribution of Working Group 1 to the Third Assessment Report of the Intergovernmental Panel on Climate Change (IPCC). Cambridge University Press: Cambridge.

[9] Climate Change Solutions. nd. Climate change solutions for small to medium-sized enterprises. http://www.climatechnagesolutions.com/ emglish/sme/default.htm. 12/07/03. 
[10] Duncan, K. 2006. Climate change, health, and women. Climate Change and Health Impacts Atlantic Conference 2006. St. John's, Newfoundland and Labrador, March 23-24, 2006.

[11] Women's Environment and Development Organization. 2004. Gender differences in water use and management. http://www.wedo.org/sus dev /untapped3.htm. 14/05/04.

[12] World Health Organization. Nd. Water as a human right. http://www.who.int/water_sanitation_health/en/rtw1.pdf. 12/05/04.

[13] Jahnavi, T. 2003. India's village women fight to protect water. http://www.peopleandplanet.net/doc.php?id=1884. 14/05/04.

[14] Kumar, P. and Clark, M. 1987. Clinical Medicine. Bailliere Tindall: London.

[15] Meade, M., Florin, J. and Gesler, W. 2000. Medical Geography. Guildford: New York.

[16] Roehr, U. 2005. Gender and climate change. Why it makes a difference. http://unfccc.int/files/meetings/cop 11/climate talk series/application/pdf /cop11 kiosk roehr-hemmati.pdf. 29/07/06.

[17] Houghton, J., Filho, L., Callender, B. et al. 1995. Climate Change 1995: The Science of Climate Change. Contribution of Working Group 1 to the Second Assessment Report of the Intergovernmental Panel on Climate Change (IPCC). Cambridge University Press: Cambridge.

[18] Intergovernmental Panel on Climate Change. 2006. Press information note. Preparations for fourth assessment report still underway. http://www.ipcc.ch/press/pr02052006.htm. 30/07/06.

[19] Cohen, S. and Miller, K. 2001. North America. In: McCarthy, J., Canziani, O., Leary, N. et al. Climate Change 2001: Impacts, Adaptation, and Vulnerability. Contribution of Working Group 11 to the Third Assessment Report of the Intergovernmental Panel on Climate Change (IPCC). Cambridge University Press: Cambridge.

[20] McCarthy, J., Canziani, O., Leary, N. et al. 2001. Climate Change 2001: Impacts, Adaptation, and Vulnerability. Contribution of Working Group 11 to the Third Assessment Report of the Intergovernmental Panel on Climate Change (IPCC). Cambridge University Press: Cambridge.

[21] McMichael, A. and Haines, A. 1997. Global climate change: the potential effects on health. British Medical Journal 315:805-9.

[22] Duncan, K., Guidotti, T., Cheng, W. et al. 1998. Health Sector. In The Canada Country Study: Climate Impacts and Adaptation. Koshida, G. and Avis, W. Environment Canada: Ottawa. pp. 501-590.

[23] World Health Organization. 2003. Climate Change and Human Health Risks and Responses. WHO: Geneva.

[24] Mannion, A. 1997. Global Environmental Change. Longman Scientific \& Technical: Harlow.

[25] Hidore, J. 1996. Global Environmental Change: Its Nature and Impact. Prentice Hall: Upper Saddle River.

[26] Ahrens, C. 2000. Meteorology Today: An Introduction to Weather, Climate, and the Environment. Thomson Learning: Pacific Grove. 
[27] Dockery, D., Cunningham, J., and Damokosh, A. 1996. Health effects of acid aerosols on North American children: respiratory symptoms. Environmental Health Perspectives 104 (5): 500-505.

[28] Dhara, V. and Dhara, R. 2002. The Union Carbide disaster in Bhopal: a review of health effects. Environmental Health 57 (5): 391-404.

[29] United Nations Department of Economic and Social Affairs. 2002. Global challenge global opportunity: trends in sustainable development. http://www.johannesburgsummit.org/html/documents/summit_does/critica ltrends_1408.pdf. 19/10/02.

[30] Regional Office for Latin America and the Caribbean. 2000. GEO Report for Latin America and the Caribbean-Environmental Outlook 2000. UNEP/ROLAC: Mexico City.

[31] Stieb, D., Pengelly, L., and Arron, N. 1995. Health effects of air pollution in Canada: expert panel findings for the Canadian Smog Advisory Program. Canadian Respiratory Journal 2: 155-160.

[32] Chen, L., Knutsen, S., Shavlik, D. et al. 2005. The association between fatal coronary heart disease and ambient particulate air pollution: are females at greater risk? Environmental Health Perspectives 113 (12): 1723-9.

[33] Suzuki, D. 2002. Expanding the health care debate. Canadian Medical Association Journal 166(13): 1678 - 9.53.

[34] Patz, J. and Kahliq, M. 2002. Global climate change and health: challenges for future practitioners. Journal of American Medical Association 287(17):2283.

[35] Burnett R., Dales R., Krewski D. et al. 1995. Associations between ambient particulate sulfate and admissions to Ontario hospital for cardiac and respiratory diseases. American Journal of Epidemiology 142(1):1522.

[36] Burnett R., Brook J., Smith Doiron, M et al. 1999. Effects of particulate and gaseous air pollution on cardiorespiratory hospitalizations. Archives of Environmental Health 54(2):130-9.

[37] Bransford, K., and Lai, J. 2002. Global climate change and air pollution: common origins with common solutions. Journal of American Medical Association 287(17):2285.

[38] MMWR. 1984. Heat-associated mortality-New York City. MMWR July 27, 1984: 33 (29):430-2.

[39] Simister, J. and Cooper, C. 2005. Thermal stress in the USA: effects on violence and employee behaviour. Stress and Health 21 (1): 3-15. 